\title{
T839 Fiber Tracking Transporter at New Muon Lab
}

\author{
J. Krider \\ Fermilab Physics Section \\ Fermi National Accelerator Laboratory \\ P.O. Box 500, Batavia, Illinois 60510
}

October 1991 


\section{Disclaimer}

This report was prepared as an account of work sponsored by an agency of the United States Government. Neither the United States Government nor any agency thereof, nor any of their employees, makes any warranty, express or implied, or assumes any legal liability or responsibility for the accuracy, completeness, or usefullness of any information, apparatus, product, or process disclosed, or represents that its use would not infringe privately owned rights. Reference herein to any specific commercial product, process, or service by trade name, trademark, manufacturer, or otherwise, does not necessarily constitute or imply its endorsement, recommendation, or favoring by the United States Government or any agency thereof. The views and opinions of authors expressed herein do not necessarily state or reflect those of the United States Government or any agency thereof. 
T839 FIBER TRACKING TRANSPORTER AT NEW MUON LAB J. Krider, Fermilab Physics Section

$10 / 23 / 91$

INTRODUCTION

A darkbox and its transporter have been designed for T839 fiber tracking tests. The darkbox is $3.35 \mathrm{~m} \times 0.76 \mathrm{~m} \times 0.25 \mathrm{~m}$ $(1 \cdot w \cdot h)$ and contains a scintillating fiber ribbon suspension system and mechanical hardware to support the readout electronics. The transporter provides $3.0 \mathrm{~m}$ of horizontal motion transverse to the beam for linear scans of fiber characteristics. In addition, 70 degrees of rotation about a vertical axis is provided to simulate tracking of particles emanating from a collision point at lab angles in the range $0^{\circ}-70^{\circ}$. The transporter, which is located inside a radiation area, is remotely controlled to permit scanning the fiber array through the region defined by four small stationary triggering scintillators without disabling beam. The transporter rails extend 20 feet to the west beyond a gate in the radiation enclosure fencing. This provides a staging area to work on the apparatus, while the beam is on. Figure 1 shows a plan view of the location of this equipment in the New Muon (NM) hall immediately upstream of the NMSS spoilers.

\section{BACKGROUND}

The T839 scintillating fiber tracking tests at NM will include measurements of light attenuation length, detection efficiency, tracking and spatial resolution in scintillating fiber ribbons up to $3 \mathrm{~m}$ long. The ribbons will be mounted inside a large darkbox in a configuration simulating two superlayers of a central tracking detector proposed for the SSC. The test apparatus is located within a fenced radiation area near the north end of NM. In order to gain access to the apparatus, beam to all of NM must be disabled.

Multianode photomultiplier tubes, Avalanche Photodiodes (APDs) and Visible Light Photon Counters (VLPCS) will be evaluated as 
readout devices for various types of scintillating fibers. Both a Philips XP4702 (64 channel tube) and a Hamamatsu H4140 (256 channel tube) have been instrumented for the beam tests. The VLPCs are being developed by Rockwell International Corporation. They must operate at $6-7^{\circ} \mathrm{K}$ and require a liquid helium cryogenic support system. An oxford helium flow cryostat, transfer line and temperature/flow controller is now operational in a lab on WH14, and it will be used for the VLPC measurements. Because of various system constraints, the cryostat with its $2 \mathrm{~m}$ long transfer line and a 100 liter dewar of liquid helium must reside on the transporter.

The proposed detector will require $4 \mathrm{~m}$ long scintillating fibers. Since the NM test area is only large enough to accomodate $3 \mathrm{~m}$ fiber scans, the fiber support frames have been made $3.05 \mathrm{~m}$ long and will use $3.1 \mathrm{~m}$ long fibers. The attenuation of longer fibers will be characterized with a radioactive source in a darkbox on WH14.

The arrangement of fiber elements, which simulate two "superlayers" of the proposed detector, is shown in crossection in fig. 2. One "layer" consists of a lamination of four individual fiber ribbons, each consisting of sixteen $0.75 \mathrm{~mm}$ diameter by $3.0 \mathrm{~m}$ long scintillating fibers. The ribbons are offset from each other by a quarter fiber diameter for increased resolution. A "superlayer" consists of two independent parallel "layers" separated by an adjustable gap of $20-50 \mathrm{~mm}$. The final assembly is made up of two "superlayers" separated by a variable gap of $200-500 \mathrm{~mm}$.

\section{DESIGN TOLERANCES}

The mechanical design requirements for establishing and maintaining relative alignment of the four layers are driven by the resolution of each four ribbon thick "layer", which is approximately $\sigma$ $=(d / 4)(1 / \sqrt{12})=60 \mu \mathrm{m}$. The most sensitive alignment condition, referred to as planarity in this text, involves positioning one fiber from each "layer" into a common plane. We anticipate that with care the four layers can be optically aligned so that all fibers are parallel to this plane within $\pm 250 \mu \mathrm{m}$ over the $3 \mathrm{~m}$ length $( \pm 83 \mu \mathrm{rad})$, 
provided that each fiber layer has been attached to its support frame to within $\pm 50 \mu \mathrm{m}$ of a straight line. We then want the planarity to

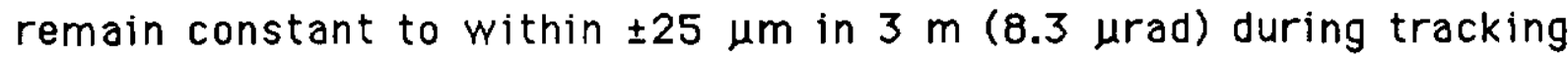
scans. The tightest tolerances are placed on deflections in the individual layer support frames, and on the torsional rigidity of the platform that supports the four layers, since these factors determine the planarity of the array.

The two sets of rails, which provide translation and rotation, are leveled and grouted in place. Deviations in the levelness of the rails produce deviations in alignment of the darkbox platform with respect to a horizontal plane and the beam axis as the transporter moves. The tolerance on this parameter is much less critical, $\pm 3 \mathrm{~mm}$ in $3 \mathrm{~m}$ ( $\pm 1 \mathrm{mrad}$ ), since the apparatus is simulating the geometry of the collider, where the finite size of the beam interaction region produces tracks with a range of origins.

\section{DESIGN - FIBER SUPPORT FRAMES}

The fiber layer support frame is constructed from a pair of $3.05 \mathrm{~m}$ long by $50.8 \mathrm{~mm}$ square aluminum extrusions with a wall thickness of $1.57 \mathrm{~mm}$. These extrusions are separated by five 50.8 $\mathrm{mm}$ tall spacers, one in the center, one $0.85 \mathrm{~m}$ either side of center, and one at each end. A layer of $60 \mu \mathrm{m}$ thick mylar is attached to one side of the support frame with silicone adhesive, and the mylar is then heat shrunk with sufficient tension to produce a flat surface. The spacers prevent excessive inward deflection of the extrusions under the load of the mylar tension.

The frame can be oriented with the mylar in a horizontal plane, to facilitate attaching the fiber layers to the mylar surface with double-sided tape, epoxy or other appropriate adhesive. Great care must be taken to align the fibers with a straight edge referenced to the frame support points, in order to produce the desired degree of straightness. In the upright mounting position with the mylar surface vertical, and fibers horizontal, the frame is supported only at the two points $0.85 \mathrm{~m}$ either side of center. These 
are the optimum support points to minimize deflections from the load of gravity. The center point and the two overhanging ends are deflected downward by the same amount, $25 \mu \mathrm{m}$. This is a dramatic reduction from the $1040 \mu \mathrm{m}$ deflection produced at the center, if the two ends of the frame were used as the support points. The finished assembly weighs about $5.9 \mathrm{~kg}$. Carbon fiber composite structures were evaluated as a lighter weight alternative to aluminum frames, but the weight savings were found to be modest, and cost was estimated to be a factor of ten higher, not including engineering time.

\section{PLATFORM AND DARKBOX DESIGN}

The part of the darkbox platform that determines fiber alignment is $1.7 \mathrm{~m}$ long by $0.6 \mathrm{~m}$ wide and supports the fiber frames at its ends. It is designed to have a high torsional rigidity to maintain the required planarity of the fiber layers. It is fixed to the lower structure at two points near the platform edges and $0.85 \mathrm{~m}$ toward one end from center, and it is free to swivel about the third point $0.85 \mathrm{~m}$ to the other side of center. This three point suspension prevents any torque caused by deformations in the lower translating and rotating structures from coupling into the platform.

The core of the darkbox platform is constructed from eight $3 \mathrm{~m}$ long by $102 \mathrm{~mm}$ square aluminum tubes with $3.2 \mathrm{~mm}$ thick walls laid side by side and welded together at $0.30 \mathrm{~m}$ intervals. Mounting plates to support the four fiber frames on top and to suspend the flow cryostat below the east end, a flange around the perimeter to attach a darkbox cover, and mounting pads to couple the platform to the lower structure, are all attached to this core. The entire darkbox and platform assembly weighs approximately $200 \mathrm{~kg}$.

The torsional rigidity of the platform about its $3 \mathrm{~m}$ long centerline was measured at Lab 6 after welding was completed. The platform was supported at three points: near both corners of one narrow end and at the center of the opposite end. Separate precision bubble levels were placed across each end and shimmed to be level. The platform was then loaded at one of the unsupported corners (a 
radial distance of $380 \mathrm{~mm}$ from the single support point) with 26 ib $(12 \mathrm{~kg})$, which produced a torque of $400 \mathrm{in}-1 \mathrm{~b}(4.6 \mathrm{~kg}-\mathrm{m})$ about the single support. The difference in level readings was observed to be $0.0010 \mathrm{inch} / f \circ 0 t$, or 83 urad of twist about the long axis of the platform. From this number, the calculated deviation for a pair of initially parallel $3 \mathrm{~m}$ long fibers separated by $60 \mathrm{~cm}$ is $4.2 \mu \mathrm{m} / \mathrm{kg}$ of assymetric load at the singly supported end. Alignment is done, with the $40 \mathrm{~kg}$ darkbox cover removed, but when the cover is installed, assymetric loading is not expected to exceed $5 \mathrm{~kg}$. So the planarity of scintillating fibers should remain constant within about $20 \mu \mathrm{m}$.

The darkbox cover, which attaches to the platform, is constructed of aluminum. The top is made from a single piece of 0.81 $\mathrm{m}$ by $3.35 \mathrm{~m}$ by $3.2 \mathrm{~mm}$ thick sheet, and the $250 \mathrm{~mm}$ high side panels are $1.6 \mathrm{~mm}$ thick. A flange fabricated from aluminum angle is welded around the bottom edge. It mates with a similar flange on the perimeter of the platform. The cover is clamped in place with quick-disconnect toggle latches to facilitate removal. The light seal between the platform and the cover is $6 \mathrm{~mm}$ thick resilient foam rubber, compressed about 50\% by the tension in the clamps. All other seams in the platform and cover have been caulked with black silicone. The assembly was tested for light leaks at Lab 6.

\section{DARKBOX TRANSPORTER DESIGN}

Fig. 3 shows the darkbox and transporter assembly. The darkbox transporter consists of two parts. A rigid I-beam base section rides on four casters which travel on rails grouted into the floor. The upstream rail has an inverted angle track, and the mating casters are grooved. One of the other casters is motorized to provide the translational motion. The base also carries the pivot point and the curved rail used for rotary motion. A relatively light weight trussed frame rides on top of the base. The frame spaces the darkbox to the desired elevation, carries the liquid helium dewar and provides the rotary motion.

This frame is supported at three points. The pivot point, 
which simulates the beam interaction point is offset $0.75 \mathrm{~m}$ upstream of the darkbox centerline and rides on a radial thrust bearing. Two 4 inch diameter castors roll on the curved rail at a radius of $2.44 \mathrm{~m}$ from the pivot. The caster which bears the heavier load is motor driven. To prevent tipping of the relatively unstable assembly, a roller tracks on the under side of the curved rail, directly below the less loaded caster.

The transporter elements were designed to maintain the levelness of the darkbox platform within \pm 1 mrad over the full range of motion. Three sets of alignment data verify that the design tolerances were achieved. The full range of variation in the elevation of the two rails used for translation was measured to be $\pm 0.4 \mathrm{~mm}$. since the minimum distance between any pair of the four translation wheels is $2.5 \mathrm{~m}$, the "worst case" level variation during translation is calculated to be $0.4 \mathrm{~mm} / 2500 \mathrm{~mm}=0.13 \mathrm{mrad}$. The variation in elevation of the curved rail was measured to be $\pm 0.6 \mathrm{~mm}$. The separation between the two rotation wheels is $1.8 \mathrm{~m}$, so the "worst case" level variation during rotation is calculated to be $0.6 \mathrm{~mm} / 1800$ $\mathrm{mm}=0.33 \mathrm{mrad}$. When the transporter was located with its pivot point on the beam line and rotated through $70^{\circ}$, the elevation of the end of the darkbox platform $3 \mathrm{~m}$ from the pivot point remained constant to within $\pm 0.4 \mathrm{~mm}$.

MOTOR DRIVES AND POSITION READBACK

The components of the two drive systems are the same. A 400 oz-in stepping motor is coupled through a torque limiter to a 12.5:1 speed reducer. The reducer output is coupled to the drive wheel through half-inch pitch roller chain and sprockets. The motors are manually operated using a standard Fermilab Research Division stepping motor controller. The nominal velocity of both drives has been chosen to be $1 \mathrm{inch} / \mathrm{s}$, although the motor step rate can easily be changed.

Translational and rotational position readback is accomplished with position displacement transducers. These devices 
consist of a cable helically wound on a drum which is attached to a multiturn potentiometer. A regulated power supply provides the reference voltage across the potentiometers. The variable voltage from each transducer is displayed on a DVM located in the same rack as the motor controllers. Fig. 4 shows one channel of the position readback circuit. Trim potentiometers provide adjustment of the zero point and scale of the transducer signal. These corrected voltages are connected to the motor controller to allow closed loop motor control. The east-west translation transducer range is 150 inches and the display has been scaled to read 0.010 volt/inch. The rotation transducer range is 100 inches and it rides in a track with a radius of 30.0 inches. Its display has been scaled to read 0.010 volt/degree. Accuracy is $\pm 0.1 \%$ of the full scale range of each device, which corresponds to \pm 0.15 inch for translation and $\pm 0.19^{\circ}$ for rotation.

\section{RADIATION AREA ACCESSES}

Two parts of the apparatus inside the radiation area require occasional access. The liquid helium dewar must be changed approximately once every three days of cryostat operation. This is a 6 hour task. At most 13 dewar changes are anticipated during the 5 month run. The preamplifier electronics, and the transporter, may require intermittant servicing. Occasional brief tasks can be completed with a controlled Access procedure scheduled at a convenient time for all NM users, such as when beam is not available or when E665 is not running. However, a different procedure is required to allow the longer tasks to be completed without disabling the beam to other users for an extended period.

A $10 \mathrm{ft}$ wide interlocked gate has been installed on the west side of the radiation area to permit removal of the apparatus to an unrestricted staging area. When the gate is opened to drive the apparatus in/out, radiation safety interlocks will trip, because the 4 minute operation exceeds the 45 second time limit imposed on Controlled Access door openings. A Search and secure must follow, prior to restoring the beam. The procedure will disable beam for 
about 15 minutes.

\section{ACKNOWLEDGEMENTS}

The Research Division Mechanical Engineering Department contributed a considerable effort to this project. Bill strickland worked from my conceptual design drawings to produce a set of formal drawings on the CAD system. Dick Smith assisted him with some of the detailing. Ron Williams used a solid modeling program to produce assembly views of the hexahedral trussed frame and details of each truss.

Carlos Hojvat provided Research Facilities Department resources. Bud Koecher coordinated all of the mechanical assembly work for the project, and he supervised fabrication the darkbox and its platform at Lab 6 . Bud also fabricated the fiber support frames and attached the fiber ribbons to them. K. C. Cahill assembled the position readout system.

Don Carpenter's group constructed the rails, base and trussed frame at MAB. His workers commissioned the apparatus at $M A B$ and moved it to NM for final installation. Dick Worland's group modified the radiation fencing, added the access gate between the staging area and the beam area and grouted the transporter rails.

Wayne Johnson from the Research Division Electrical Group provided the motor controller and the associated motor and limit switch wiring.

John Elias and Stephen Pordes assisted with editing this article. 
9.

\section{LIST OF FIGURES}

1. Installation at NM

2. Cross sectional view of two superlayers

3. Darkbox and transporter assembly

4. Position readback electrical circuit 
Fig. 1 T839 Layout at NM
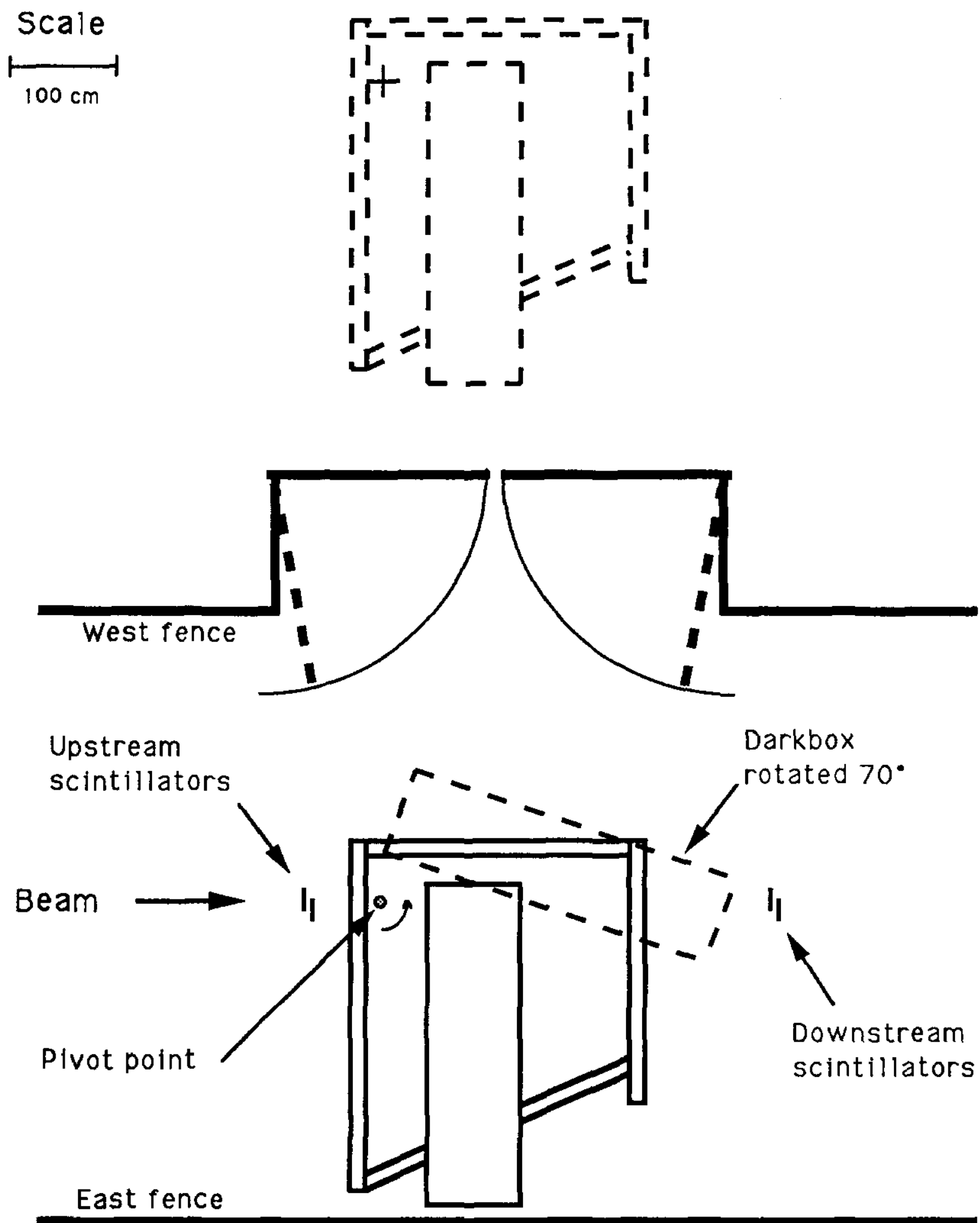
Fig. 2 Cross section of superlayers

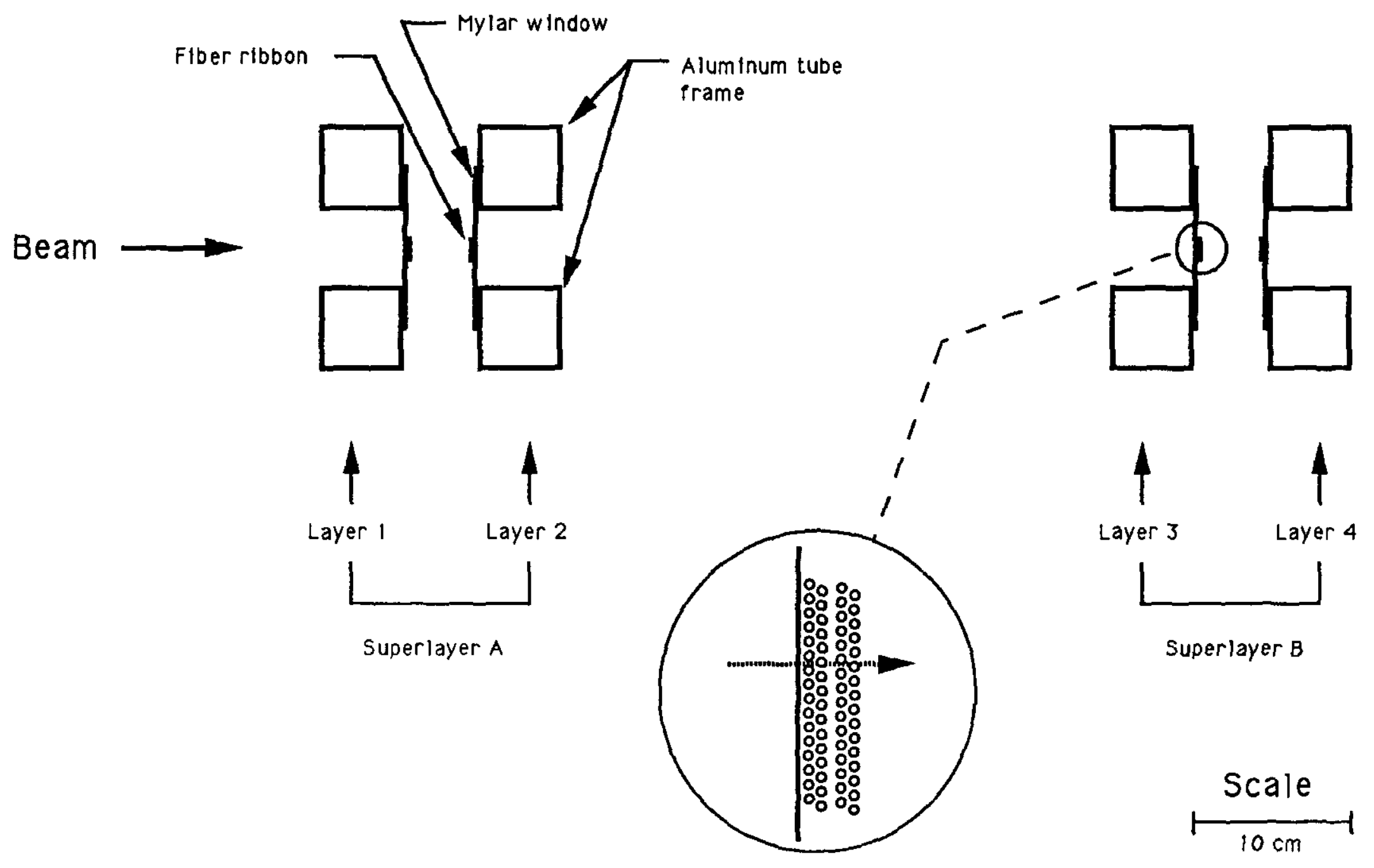




\section{Fig. 3 Darkbox and transporter assembly}

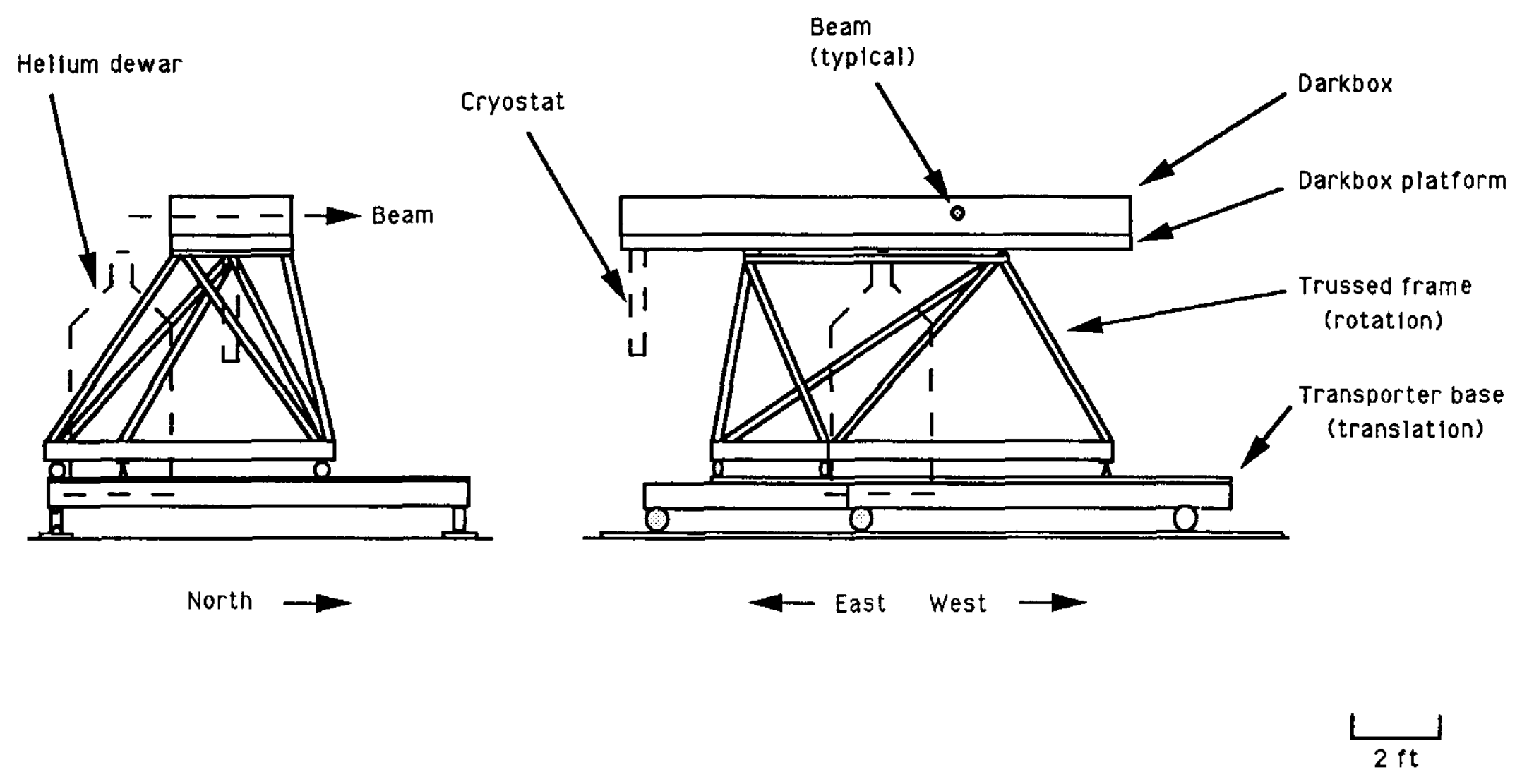


Fig. 4 Position readback circuit

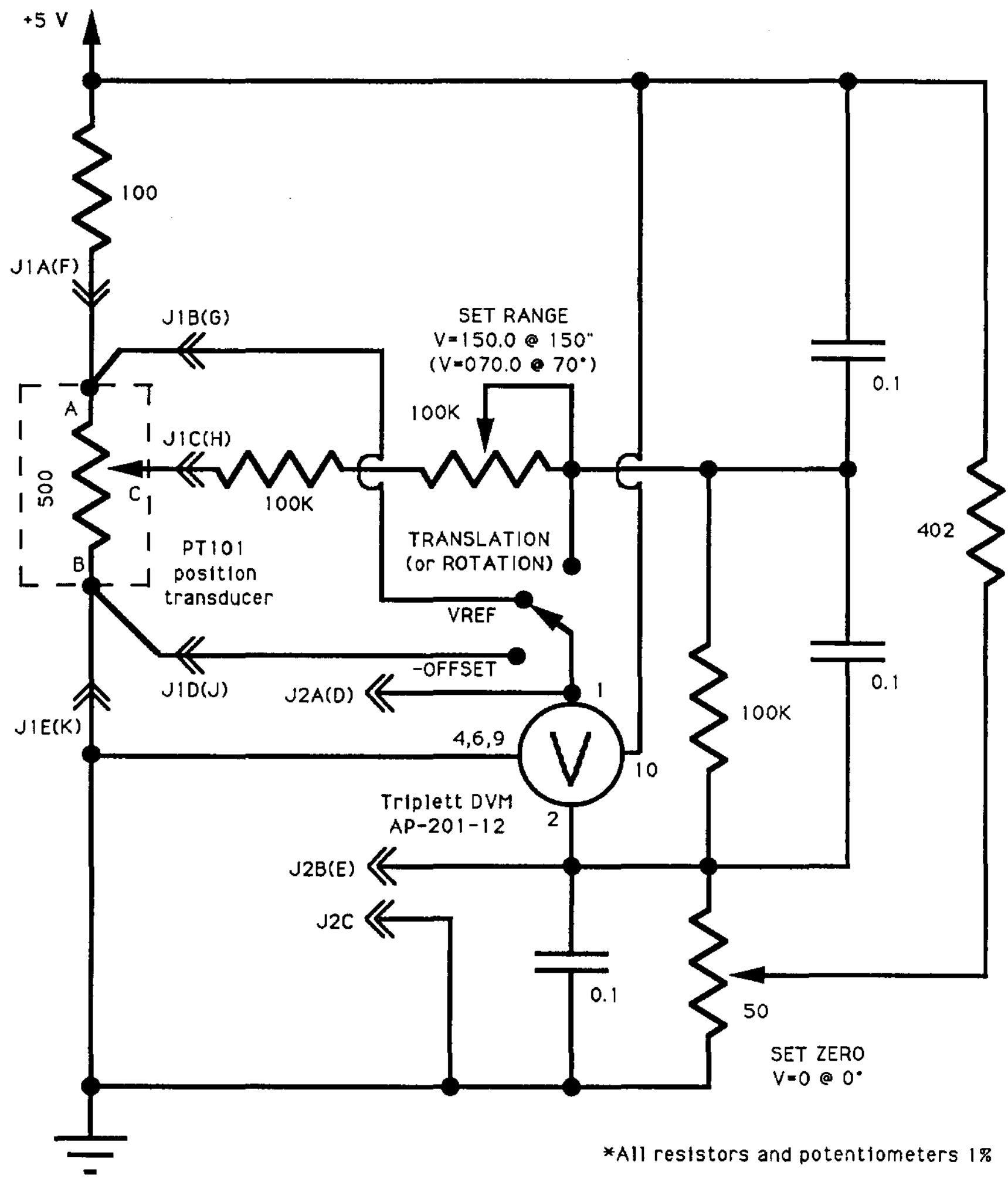

